\title{
Propagation of planetary-scale zonal mean wind anomalies and polar oscillations
}

\author{
QIAN WeiHong ${ }^{*}$ \& LIANG HaoYuan \\ Department of Atmospheric and Oceanic Sciences, School of Physics, Peking University, Beijing 100871, China
}

Received October 27, 2011; accepted December 26, 2011; published online May 6, 2012

\begin{abstract}
Global atmospheric variables can be physically decomposed into four components: (1) the zonal time averaged climate symmetric component, (2) the time averaged climate asymmetric, (3) the zonal-mean transient symmetric anomaly, and (4) the transient asymmetric anomaly. This study analyzes the relationships between the intra-seasonal and inter-annual variability of planetary scale decomposed zonal and meridional winds in the tropopause, and oscillations such as those from the El Niño-Southern Oscillation (ENSO), the Arctic Oscillation (AO) and the Antarctic Oscillation (AAO). The tropical inter-annual zonal mean wind anomalies in the tropopause are linked with the ENSO cycle and can propagate into the subtropics, mid-latitudes, and polar front regions via abnormal meridional vertical cells. Similarly, tropical intra-seasonal (40-60-d) zonal wind anomalies can reach the subtropics and mid-latitudes. The polar intra-seasonal zonal wind anomalies in the tropopause can propagate toward high-latitude areas. Thus, the AO and the AAO are the result of the interaction and propagation of these planetary scale zonal wind anomalies.
\end{abstract}

physical decomposition, El Niño-Southern Oscillation, Arctic Oscillation, Antarctic Oscillation, planetary scale, intraseasonal oscillations

Citation: Qian W H, Liang H Y. Propagation of planetary-scale zonal mean wind anomalies and polar oscillations. Chin Sci Bull, 2012, 57: 2606-2614, doi: 10.1007/s11434-012-5168-1

The first quantitative description of the way that the mid-latitude atmospheric circulation can change was introduced by Rossby [1]. It is known as the "westerly circulation index" (or Rossby zonal index) and was defined as the average geostrophic zonal wind between latitudes $35^{\circ} \mathrm{N}$ and $55^{\circ} \mathrm{N}$. Atmospheric circulation in the middle troposphere around mid-latitudes often maintains a straightforward westerly circulation via a high phase of the Rossby zonal index, and at other times via a low phase condition when large scale circulation anomalies with meridional fluctuations occur. Ten years ago, the Arctic Oscillation (AO) [2,3] and Antarctic Oscillation (AAO) [4] were identified. These two planetary scale oscillations show a see-saw like interplay between adjacent mean zonal wind anomalies on intra-seasonal to inter-annual timescales. There are two zonal bands of significant positive and negative correlations that

*Corresponding author (email: qianwh@pku.edu.cn) associate the AO (or AAO) series with the monthly zonal-mean sea level pressure, geopotential height, zonal wind at $500 \mathrm{hPa}$, and air temperature at $1000 \mathrm{hPa}$ [5] in each hemisphere. Enhanced Ferrel and Hadley cell activity manifest themselves in meridional vertical circulation anomalies consistent with the AO symmetric mode in both winter and summer seasons [6]. It can be concluded that the Rossby zonal index represents changes in the strength of zonal wind, while the AO and AAO indices characterize the opposite pressure changes within and without the polar areas. They all reflect gradient variations of zonal mean geopotential height (or pressure) in the mid- and high-latitudes. These planetary scale oscillations directly impact the weather and climate in East Asia and China [7-10].

In the tropical Pacific, the tropospheric inter-annual variability of the Walker cell is linked with El Niño events (oceanic warming). It is directly associated with the Southern Oscillation (SO) [11-13], and therefore called the in- 
ter-annual El Niño-Southern Oscillation (ENSO) cycle. The phase lag relationship from inter-annual anomalies of the equatorial Pacific sea surface temperature (SST), the equatorial zonal wind angular momentum, and the solid Earth angular momentum, was established by the role of largescale mountain torque and air-mass delivery through the Walker cell [14]. The ENSO index, which characterizes the phase and strength of inter-annual ENSO cycle, reflects changes in the equatorial Pacific SST and a sea surface pressure oscillation, rather like a standing-wave oscillation, on two fixed locations between the tropical Eastern and Western Hemispheres. On the other hand, the intra-seasonal (or 40- to 50-day) oscillation also often appears in the tropical atmosphere. First reported by Madden and Julian $[15,16]$ in the early 1970s, this tropical atmospheric low-frequency oscillation (MJO) propagates eastward.

Although these circulation indices including the Rossby zonal index, the ENSO index, the AO and AAO indices, and even the MJO, are widely used for the analysis and prediction of abnormal weather and climate, they are not well understood. It is commonly believed that extreme weather or abnormal climate events are both affected by equatorial El Niño (or La Niña) events, and equally, extreme events are closely linked with the AO, AAO, MJO and other atmospheric oscillations. Therefore, from both a theoretical and practical standpoint, further understanding of these systems is crucial.

\section{Methods and datasets}

This work used the global daily atmospheric wind data from NCEP/NCAR Reanalysis 1 [17]. This dataset has a geographical resolution of $2.5^{\circ} \times 2.5^{\circ}$ from January 1980 to May 2011 and has 12 layers of pressure (including 1000, 925, $850,700,600,500,400,300,250,200,150$ and $100 \mathrm{hPa}$ ). The time series of the AAO index for 1979 to 2010 and the AO index for 1950 to 2010 have monthly resolution and were calculated by the empirical orthogonal function (EOF) mode based on the $700 \mathrm{hPa}$ and $1000 \mathrm{hPa}$ geopotential height anomalies. ERSST.V3B SST [18] anomalies in the Niño 3.4 region $\left(5^{\circ} \mathrm{N}-5^{\circ} \mathrm{S}, 170^{\circ}-120^{\circ} \mathrm{W}\right)$ were used to identify the impact of the ENSO cycle. Time series of the $\mathrm{AO}, \mathrm{AAO}$ and ENSO indices were obtained from the U.S. National Oceanic and Atmospheric Administration's website (http://www.cpc.ncep.noaa.gov/).

Global atmospheric variables can be physically decomposed into four components: the zonal-time averaged climate symmetric; the time averaged climate asymmetric; the zonal mean transient symmetric anomaly; the transient asymmetric anomaly [19]. The first two components are caused by seasonal changes of solar radiation and sea-land thermal distribution, and together, they constitute the regular daily climate. The third component can be regarded as a planetary-scale index cycle of atmospheric variables that is forced by the thermal contrast between polar and equatorial areas. The fourth component contains complex regional-scale transient anomalies.

This work focuses on the third component, i.e. the planetary scale zonal mean transient anomalies in the atmosphere. Hence, the daily climate components are removed from the whole variable observations. For example, the planetary scale transient anomaly of zonal mean zonal wind in the year $Y$ and the calendar day $t$ is [19]:

$$
[U(\varphi, t)]_{Y}^{\prime}=\sum_{\lambda=1}^{K} U(\lambda, \varphi, t)_{Y} / K-\left[\bar{U}_{t}(\varphi)\right] .
$$

The variable $U(\lambda, \varphi, t)_{Y}$ in eq. (1) is the historical or current meteorological observations of zonal wind in the calendar day $t$ of the year $Y$ at the position of longitude $\lambda$ and latitude $\varphi$.

The component $\left[\bar{U}_{t}(\varphi)\right]$ is the climate zonal-mean zonal wind averaged from total $N$ years at the day $t$ and changes with latitude $\varphi$. Its mathematical expression is as follows:

$$
\left[\bar{U}_{t}(\varphi)\right]=\sum_{\tau=1}^{N} \sum_{\lambda=1}^{K} U_{t}(\lambda, \varphi, \tau) /(N \times K) .
$$

This climate component is determined by the seasonal cycle of solar radiation. $\tau$ is the number of years from 1 to $N ; N$ is the total years with all historical data used to calculate the daily climate; and $\lambda$ is the grid longitude number from the first to the last $(K=144)$.

\section{Results}

The planetary-scale zonal-mean transient symmetrical wind anomalies component is calculated using eq. (1). Figure 1 shows the vertical profile of standard deviations of daily zonal-mean transient zonal wind anomalies $(U)$ and meridional wind anomalies $(V)$ over the 100 to $1000 \mathrm{hPa}$ from the South Pole to the North Pole. A maximum center of standard deviation $(0.77 \mathrm{~m} / \mathrm{s})$ of the daily zonal-mean meridional wind anomalies appears near the equatorial tropopause (150 $\mathrm{hPa}$ ), and decreases to $300 \mathrm{hPa}$ at the two poles. If monthly mean instead of daily meridional wind anomalies were used, the distribution of monthly standard deviations is similar to Figure 1(a), but the value at the equatorial tropopause is only $0.45 \mathrm{~m} / \mathrm{s}$. For the daily mean zonal wind anomalies, the standard deviation calculated is shown in Figure 1(b). The maximum values at different latitudes are located near the tropopause, but the largest center is not located in the equatorial tropopause. The largest standard deviation center (5.1 $\mathrm{m} / \mathrm{s}$ ) in the Southern Hemisphere is located at $60^{\circ} \mathrm{S}$ and at the $300 \mathrm{hPa}$ altitude. Moreover, there are other high value centers near $30^{\circ} \mathrm{S}, 45^{\circ} \mathrm{S}$ and the South Pole. The largest center $(6.9 \mathrm{~m} / \mathrm{s})$ in the Northern Hemisphere is near the 300 

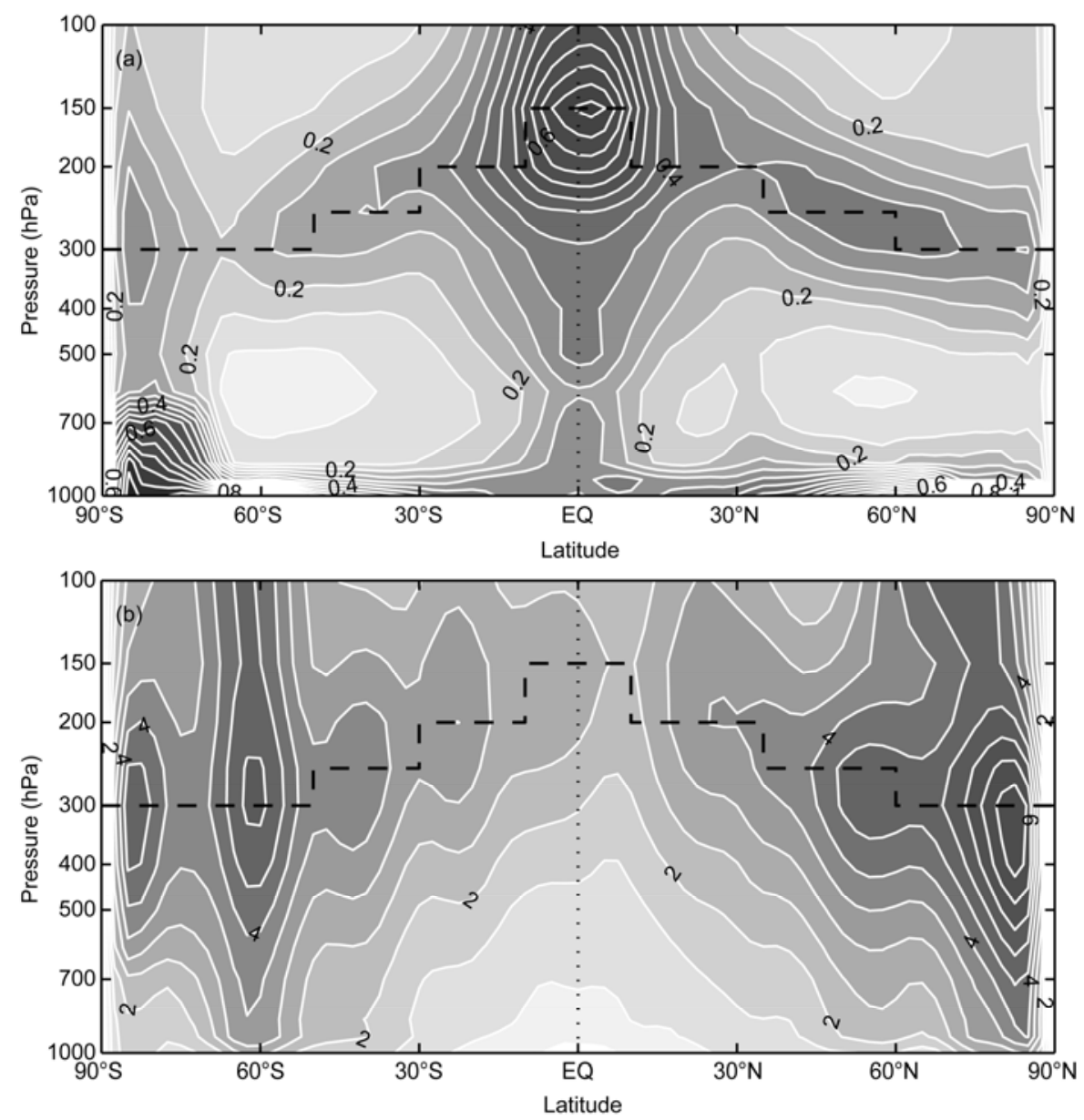

Figure 1 The latitude-pressure profiles of standard deviation $(\mathrm{m} / \mathrm{s})$. Zonal-mean anomalies of daily meridional wind (a) and daily zonal wind (b) based on the data for 1981 to 2010. The dashed line goes through the maximum standard deviations near the tropopause.

hPa over the Arctic. Other high value centers between $30^{\circ} \mathrm{N}$ and $50^{\circ} \mathrm{N}$ above the tropopause are also present. The standard deviations calculated by daily and monthly planetary scale mean zonal wind anomalies also have a similar distribution.

Wind anomalies at three grids across $2.5^{\circ} \mathrm{S}$ to $2.5^{\circ} \mathrm{N}$ at $150 \mathrm{hPa}$ were averaged to generate a daily time series, from which was calculated the monthly time series. The daily and monthly series of meridional wind anomalies near the equatorial troposphere for 1981 to 2010 are shown in Figure 2 . The meridional wind anomalies have significant fluctuations during 1982 to 1983 and 1997 to 1998. These appear to coincide with strong ENSO signals.

Figure 1(b) shows 7 areas with high values of zonal wind anomalies from the south to north poles over the tropopause. The grid-point groups of these areas were ordered by numbers and with their locations are given in Table 1. The time series of each grid-point group were calculated using zonal wind anomalies (not shown). The correlation coefficients of these time series are given in Table 2. Negative correlations between two adjacent series of high-latitude regions in both hemispheres could reflect phase lag relationships. Similarly, there are also negative correlations in the same time or lagged positive correlations between the time series of the two groups in the subtropical and mid-high-latitudes, reflecting the meridional propagation of zonal wind anomalies. The two adjacent series (Ud and Ue) of zonal wind anomalies in the subtropics of both hemispheres are positively correlated $(P<0.01)$ with a correlation coefficient of 0.5 .

Figure 3 shows the relationship between the monthly meridional wind anomalies over the equatorial tropopause and the monthly zonal wind anomalies averaged over the two subtropical tropopauses. Zonal wind leads meridional wind anomalies by 1 and 2 months, with correlation coefficients of 0.18 and 0.19 respectively. Their correlation coefficient is 0.15 simultaneously, with $P<0.01$ in all cases. The zonal and meridional wind anomalies have almost the same phase in the tropical tropopause, and hence might share the same forcing mechanism(s). Zonal wind anomalies are observed when there are significant SST anomalies in the central and eastern equatorial Pacific, so were very obvious during 1982 to 1983,1986 to 1987,1992 to 1993,1997 to 1998, 2004 to 2005 and 2009 to 2010 . Meridional wind anomalies are not always as obvious as those of the zonal 


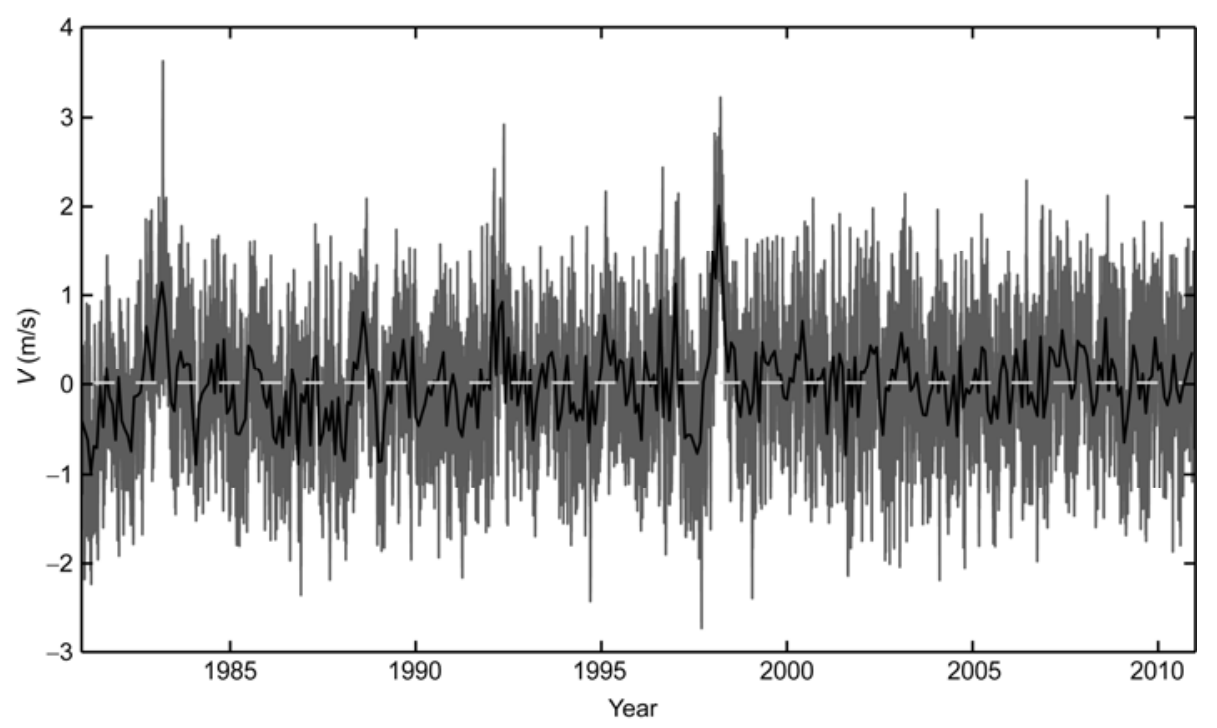

Figure 2 The zonal mean anomalies ( $\mathrm{m} / \mathrm{s}$ ) of daily (grey line) and monthly (black line) meridional winds near the equatorial tropopause (150 hPa).

Table 1 Seven major centers with their serial numbers, pressure levels, latitudes and grids shown in Figure 1(b)

\begin{tabular}{cccc}
\hline No. & Pressure level $(\mathrm{hPa})$ & Latitude & Grids \\
\hline a & 300 & $85^{\circ}-82.5^{\circ} \mathrm{S}$ & 2 \\
$\mathrm{~b}$ & $250-300$ & $62.5^{\circ}-60^{\circ} \mathrm{S}$ & 4 \\
$\mathrm{c}$ & $200-250$ & $42.5^{\circ}-40^{\circ} \mathrm{S}$ & 4 \\
$\mathrm{~d}$ & $150-200$ & $22.5^{\circ}-20^{\circ} \mathrm{S}$ & 4 \\
$\mathrm{e}$ & $150-200$ & $25^{\circ}-27.5^{\circ} \mathrm{N}$ & 4 \\
f & $250-300$ & $52.5^{\circ}-55^{\circ} \mathrm{N}$ & 4 \\
$\mathrm{~g}$ & 300 & $77.5^{\circ}-80^{\circ} \mathrm{N}$ & 2 \\
\hline
\end{tabular}

wind, and sometimes are not observed when might be expected, e.g. 2009 to 2010.

\section{Meridional propagation of zonal wind anom- alies}

Planetary scale transient mean zonal wind anomalies in the tropopause have some characteristics that might suggest they would propagate with latitude (Table 2). Figure 1(b) shows a time-latitude section, displaying such meridional propagation. Figure 4 shows zonal wind anomalies for the period 1981 to 2010. Some sources of zonal mean wind anomalies which were symmetric relative to the equator can be seen near the tropical tropopause. Concurrent with large ENSO events, some large amplitude zonal wind anomalies appeared in 1981 to 1983,1997 to 1998 , and 2009 to 2010. These planetary-scale zonal wind anomalies are delineated by the long dashed lines with arrows. In early 1981, a planetary scale zonal wind anomaly propagated from the equator and arrived at the subtropics and grew in early 1983. It reached the mid- and high-latitudes in early 1984 and early 1985, respectively. The whole process lasted about 4-5 years. During this period, another planetary scale zonal wind anomaly from the equator in the early summer of 1982 , and quickly propagated to the high-latitudes by the fall of 1982. In the early summer of 1986, an inter-annual low-frequency zonal mean wind anomaly from the equator and propagated in the Southern Hemisphere for about 4 years. During the summer to fall seasons, it reached the subtropics, mid- and high-latitudes during 1987, 1988, and 1989. Figure 4 also shows planetary scale zonal wind

Table 2 Simultaneous correlation coefficients between the 7 series of zonal mean wind anomalies near the tropopause and AO, AAO, Niño3.4 SST anomaly indices for the period 1981 to 2010

\begin{tabular}{|c|c|c|c|c|c|c|c|c|c|}
\hline & $\mathrm{AO}$ & $\mathrm{Ug}$ & Uf & $\mathrm{Ue}$ & Niño3.4 & $\mathrm{Ud}$ & $\mathrm{Uc}$ & $\mathrm{Ub}$ & $\mathrm{Ua}$ \\
\hline AAO & 0.04 & -0.04 & 0.07 & -0.15 & $-0.22 * *$ & $-0.18 * *$ & $-0.51 * *$ & $0.87 * *$ & $-0.28 * *$ \\
\hline $\mathrm{Ua}$ & 0.02 & 0.07 & -0.03 & 0.05 & $0.12 *$ & 0.08 & $0.21 * *$ & $-0.35 * *$ & \\
\hline $\mathrm{Ub}$ & 0.03 & -0.04 & 0.06 & $-0.13 *$ & $-0.20 * *$ & -0.07 & $-0.76^{* *}$ & & \\
\hline $\mathrm{Ud}$ & -0.06 & 0.00 & -0.09 & $0.50 * *$ & $0.55^{* *}$ & & & & \\
\hline Niño3.4 & -0.08 & 0.00 & -0.08 & $0.63 * *$ & & & & & \\
\hline $\mathrm{Ue}$ & $-0.36^{* * *}$ & 0.06 & $-0.40 * *$ & & & & & & \\
\hline Uf & $0.67 * *$ & $-0.17 * *$ & & & & & & & \\
\hline $\mathrm{Ug}$ & $0.22 * *$ & & & & & & & & \\
\hline
\end{tabular}

* indicates the correlation coefficient is at the $P<0.05$ significance level, $(|r| \geqslant 0.103)$; ** indicates the coefficient is at the $P<0.01$ significance level $(|r| \geqslant 0.136)$. 


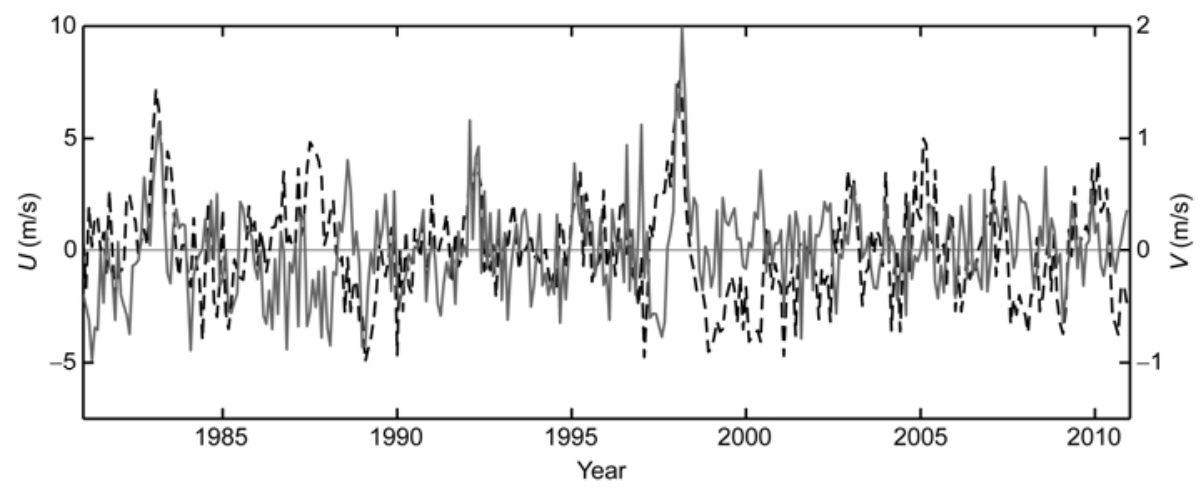

Figure 3 The monthly zonal mean wind anomalies averaged near the subtropical tropopause (dashed line) and the monthly zonal mean meridional wind anomalies over the equatorial tropopause (solid line).

anomalies of 40-60-d duration. These belong to an intra-seasonal timescale. The dotted lines indicate such zonal wind anomalies that propagated rapidly in 1982, early 1998, and 1991 to 1992 .

The strongest El Niño event of the twentieth century occurred during 1997 to 1998 [20]. In early 1997 a planetary scale inter-annual zonal wind anomaly appeared at the equator and then propagated through the subtropics, then mid- and high-latitudes in 1998, 1999 and 2000 respectively. The quasi-4-year scale of the ENSO cycle was understood as a result of inter-annual ocean-atmosphere interactions. The tropical intra-seasonal zonal wind anomalies are weakening by the time that the inter-annual zonal wind anomalies have propagated to the mid-latitudes. Differently, the tropical intra-seasonal zonal wind anomalies became strong when the inter-annual zonal wind anomalies first appeared along the equatorial zone such as the case in the early 1997. Seven relatively complete intra-seasonal zonal wind anomalies appeared in the tropics in 2002 , each with an average life of 40-60 d. The zonal wind anomalies shown in Figure 4 are filtered using a 31-d low-pass filter [21] so that the high frequency fluctuations do not appear; hence seasonal changes (i.e. the annual cycle) are removed. Oscillations with a timescale of 40-60 d can be observed in the planetary scale zonal mean wind anomalies that could propagate to subtropical and mid-latitudes. This is not the MJO, which only propagates in the tropics. The inter-annual planetary scale zonal mean wind anomalies generated in the tropics can propagate to high-latitudes, but do not often reach the poles. The intra-seasonal planetary scale zonal wind anomalies generated in equatorial regions can spread to the subtropics and mid-latitudes. In the polar atmosphere, intra-seasonal planetary scale zonal wind anomalies also, but propagate from polar regions to high-latitudes, seeing the solid arrow in Figure 4.

The intra-seasonal planetary scale zonal wind anomalies in the tropics correspond to the quasi biennial oscillation of the equatorial Pacific SST anomalies, could be clearly seen at the beginning of this century. The strongest ENSO events this century occurred in the equatorial Pacific in 2009 to
2010. During this period, both inter-annual and intra-seasonal planetary scale zonal wind anomalies have propagated from the tropics to the mid- and high-latitudes. The amplitudes of the two types of events can increase or reduce (constructive or destructive interference) when inter-annual and intra-seasonal planetary scale zonal wind anomalies generated in the tropics arrive at the same latitude simultaneously with intra-seasonal anomalies from a polar region.

Figure 4 shows meridional propagations of the zonal mean westerly (positive) anomalies associated with the warm phase of the ENSO cycle (El Niño events), and the zonal mean easterly (negative) anomalies associated with the cold phase of the ENSO cycle (La Niña events). It should be noticed that the positive planetary scale zonal wind anomaly at the equatorial tropopause appeared before the ENSO warm events (1982 to 1983), and the negative zonal wind anomaly (or easterly enhanced anomaly) occurred when the warm events matured (1997 to 1998), seeing Figure 5. The planetary scale zonal mean northerly anomalies at the equatorial tropopause before the Fall 1982 became southerly anomalies in the winter 1982-1983 and in spring to summer 1983 when the ENSO warm event matured. The meridional wind anomalies behaved similarly during the 1997-1998 El Niño events. In summary: before, during, and after an ENSO event, westerly anomalies and northerly anomalies appear near the equatorial tropopause, corresponding to the warm SST phase in the equatorial Pacific. Then westerly anomalies in the equatorial tropopause weaken and the southerlies enhance, warming the equatorial Pacific sea surface. The appearance of tropopause southerly anomalies indicates northward air-mass delivery across the equator at the high altitude or southward air-mass delivery at the lower troposphere, which is the signal of weakening of ENSO events.

\section{Causes of zonal-mean zonal wind anomalies}

To clarify the relationship between ENSO and the planetary 

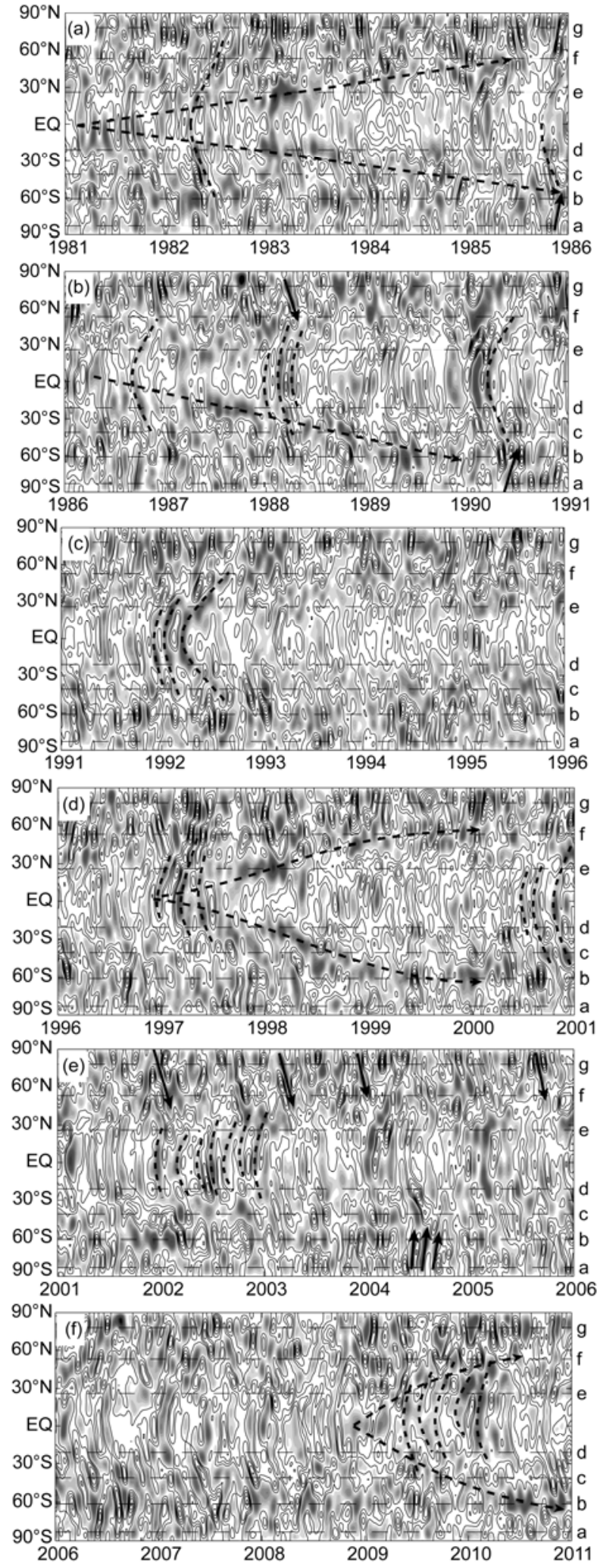

Figure 4 Variations of the zonal mean wind anomalies near the tropopause between $90^{\circ} \mathrm{S}$ and $90^{\circ} \mathrm{N}$ for the period 1981 to 2010 . The shaded areas indicate positive zonal wind (westerly) anomalies. The contour interval is $2 \mathrm{~m} / \mathrm{s}$. The fine dashed-grey lines correspond to the 7 latitudes in Table 1. The thick dotted lines show the inter-annual and intra-seasonal anomalies that originated from the tropical atmosphere, the arrows indicate the intra-seasonal anomalies that originated from the polar atmospheres.
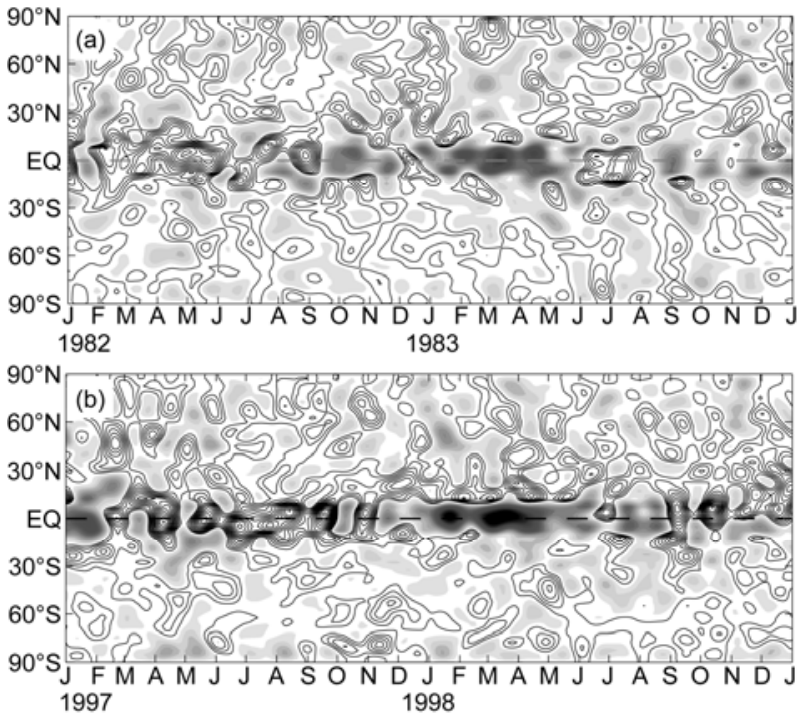

Figure 5 As in Figure 4, but for the zonal-mean meridional wind anomalies on the tropopause. (a) 1982-1983; (b) 1997-1998. The shaded areas indicate the positive meridional wind (southerly) anomalies and the contour interval is $0.1 \mathrm{~m} / \mathrm{s}$.

scale meridional wind anomalies, Figure 6(a) shows the lead-lag relationship between SST anomalies at the Niño 3.4 region and the zonal mean meridional wind anomalies over the equatorial tropopause at $150 \mathrm{hPa}$. Their correlation coefficient is $0.09(P<0.05)$ when they are simultaneous, and $0.24(P<0.01)$ when the Niño3.4 region SST anomaly series are 4 months ahead of zonal-mean meridional wind anomalies. Figure 6(b) shows their time series, but the SST series are lagged by 4 months. Statistically, there are no significant systematic relationships among the Arctic/ Antarctic Oscillations, the planetary-scale meridional wind anomalies at the equatorial tropopause, or the zonal wind anomalies in the subtropical tropopause.

The simultaneous correlation coefficients between a couple series of the Niño3.4 region SST anomaly, AO and AAO indices, and 7 chosen zonal-mean zonal wind anomalies on the tropopause for the period of 1981 to 2010 show:

(1) The zonal mean wind anomalies near the tropopause at different latitudes have a significant lag correlation, which indicates the meridional propagation characteristics of zonal mean wind anomalies.

(2) The Niño3.4 region SST anomaly and zonal-mean zonal wind anomalies in the subtropical tropopause are positively correlated with correlation coefficients of 0.55 and 0.63 for Northern and Southern Hemispheres, respectively.

(3) The AO index and zonal mean wind anomalies on the tropopause at high-latitudes between $52.5^{\circ} \mathrm{N}$ and $55^{\circ} \mathrm{N}$ have a correlation coefficient of 0.67 , while the AO index and subtropical zonal mean wind anomalies on the tropopause have a negative correlation.

(4) The AAO index and zonal mean wind anomalies at the tropopause from $60^{\circ} \mathrm{S}$ to $62.5^{\circ} \mathrm{S}$ has a correlation coefficient of 0.87 . However the AAO index is also negatively 

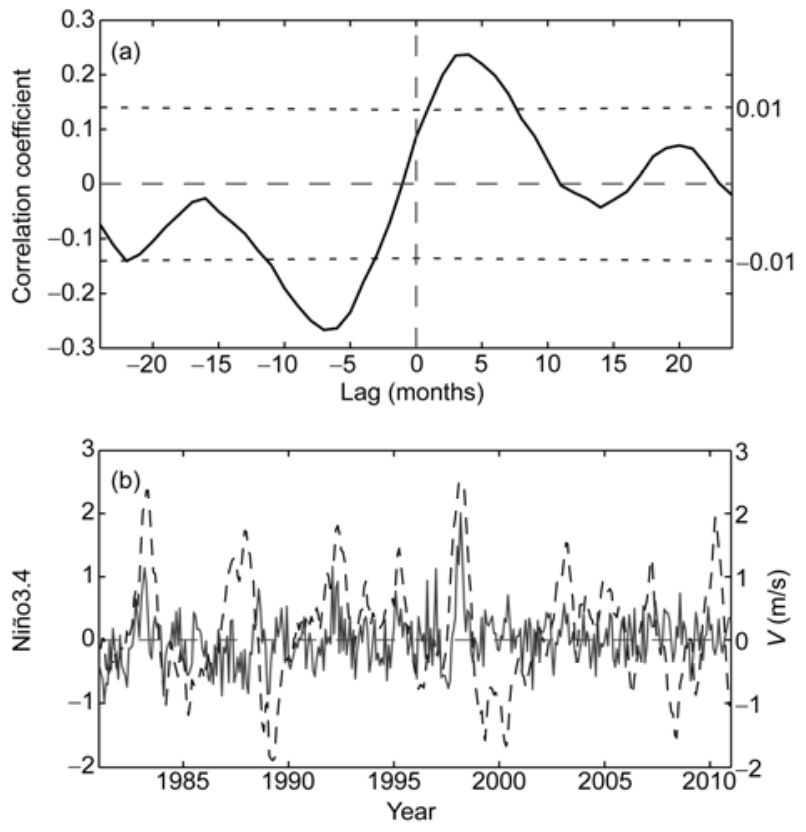

Figure 6 The lead-lag relationship between sea surface temperature anomalies at the Niño3.4 region and the zonal mean meridional wind anomalies over the equatorial tropopause at the $150 \mathrm{hPa}$ level. (a) The lead-lag correlation coefficients with months; (b) time series of meridional wind anomalies (solid line) and 4-month-lagged SST anomaly series for the Niño 3.4 region (dashed line).

correlated with the zonal mean wind anomalies in the high and mid-latitudes of the Southern Hemisphere. This correlation covers the meridional mode structure of AAO over all pressure levels from the surface to the tropopause. The correlation coefficient between the $\mathrm{AO}$ and $\mathrm{AAO}$ indices is 0.04 , which effectively means there is no correlation.

Table 2 shows the AAO index or the AO index has significant positive correlations with the planetary scale zonal mean wind anomalies in the same hemisphere near the midand high-latitude tropopause. Figure 7 shows monthly series of mid- and high-latitude zonal-mean wind anomalies near the tropopause, as well as the Arctic and Antarctic oscillation indices during 1981 to 2010. The AAO index and zonal wind anomalies over the tropopause in the South Hemisphere are closely related with the correlation coefficient of 0.87 . The correlation coefficient between the AO index and zonal wind anomalies over the tropopause in the Northern Hemisphere is 0.67 , reflecting a more complex relationship. The AO and AAO are not only the evidence of the low level zonal oscillations at mid- and high-latitudes in each hemisphere, but also their maximum signals are located near the tropopause, reflecting intensity changes of the polar fronts. The planetary scale zonal wind anomalies at mid- and high-latitudes near the tropopause indicate the changes in the planetary scale westerly jet. According to thermal wind theory, the planetary scale zonal wind anomalies on the tropopause have direct linkage with changes of the meridional temperature gradient.
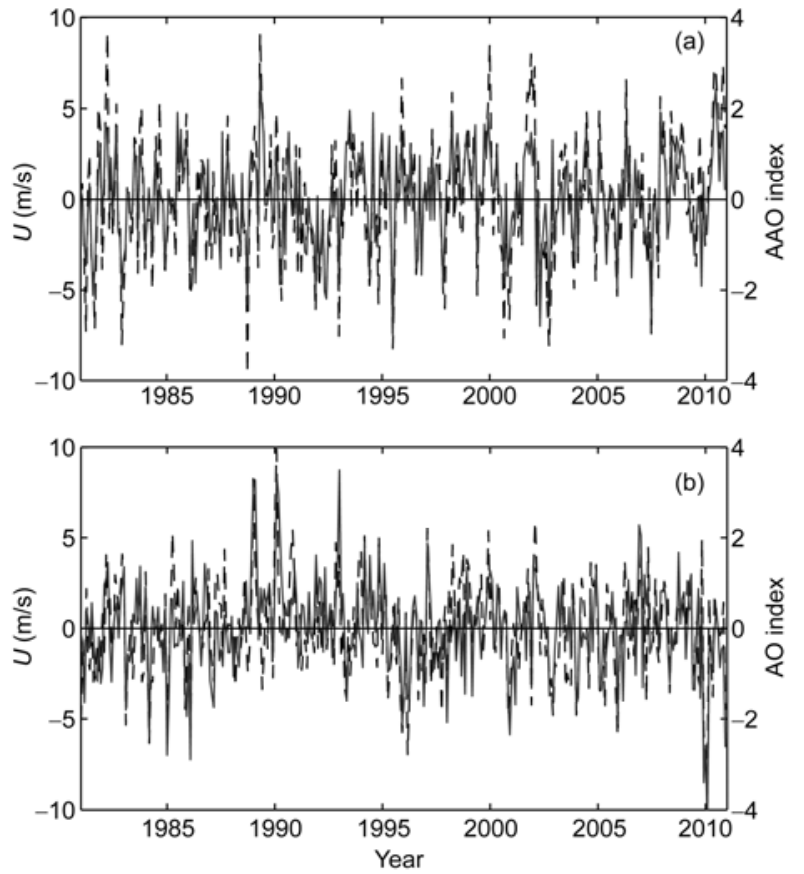

Figure 7 The series of mid- and high-latitude zonal mean wind anomalies near the tropopause (dashed line) and the Arctic/Antarctic oscillations (solid line). (a) Tropopause $(250-300 \mathrm{hPa}$ ) zonal wind anomalies in the high-latitude Southern Hemisphere $\left(62.5^{\circ}-60^{\circ} \mathrm{S}\right)$ and the AAO index series (correlation=0.87); (b) zonal wind anomalies in the mid- and high-latitude Northern Hemisphere $\left(52.5^{\circ}-55^{\circ} \mathrm{N}\right)$ and the AO index series (correlation=0.67).

\section{Conclusion}

Tropospheric wind fields have been divided into 4 parts by using a physical decomposition method. There are centers with high standard deviations of planetary scale zonal mean and meridional wind anomalies near the tropopause on timescales of day to month. A conceptual physical model of relationships between relevant indices was shown in Figure 8. A large standard deviation band of zonal and meridional wind anomalies exists near the $150 \mathrm{hPa}$ level over the equator. Its height decreases to $300 \mathrm{hPa}$ with increasing latitude to the polar region. Analyses of the propagation of zonal mean and meridional wind anomalies on different latitudes close to the tropopause, and relationships among ENSO, AO, AAO and those zonal wind anomalies mean:

(1) Planetary-scale zonal-mean meridional wind anomalies over the equatorial tropopause and zonal wind anomalies near the subtropical tropopause on both sides of the equator are positively correlated on the intra-seasonal (4060-d) and inter-annual timescales. The inter-annual meridional wind anomalies over the equatorial tropopause and zonal wind anomalies over the subtropical tropopauses are closely linked to, or driven by, the ENSO cycle. The zonal mean geostrophic zonal wind angular momentum anomalies originating in the tropics can move to other regions via meridional circulation (the Hadley and Ferrel cells) anomalies. 


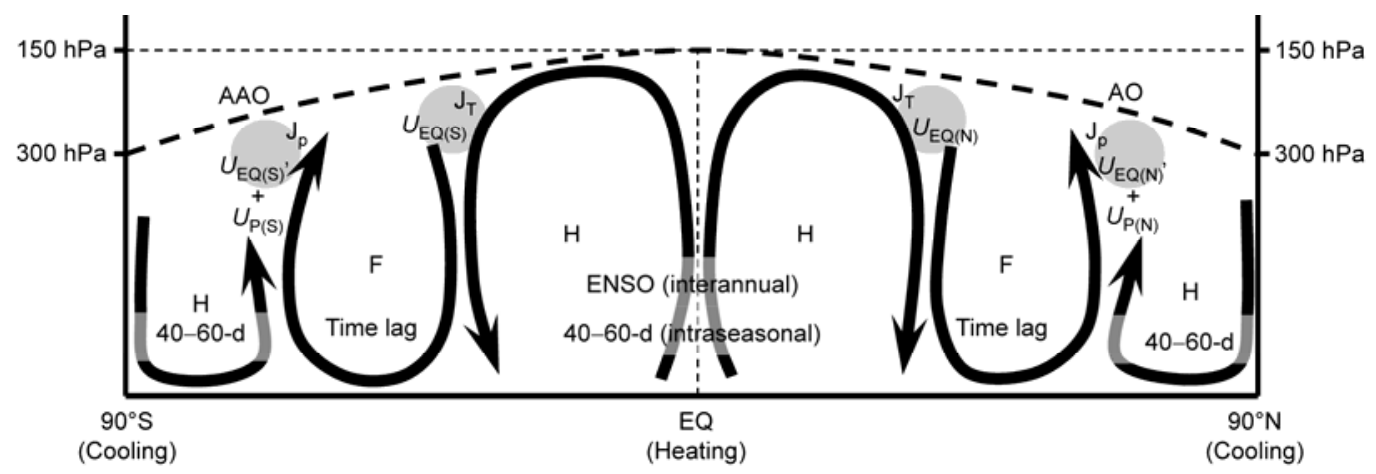

Figure 8 A conceptual physical model showed the relationship between the zonal wind anomalies $(U)$ on the tropopause at different latitudes, abnormal circulation of tropical Hadley cell $(\mathrm{H})$, mid-latitude Ferrel cell $(\mathrm{F})$, and the polar Hadley $(\mathrm{H})$ cell, abnormal subtropical jets $\left(\mathrm{J}_{\mathrm{T}}\right)$ and polar front jets $\left(\mathrm{J}_{\mathrm{P}}\right)$, the intra-seasonal (40-60-d) oscillation in the polar regions and the equatorial intra-seasonal and inter-annual oscillations as well as the ENSO cycle (heat source). $U_{\mathrm{EQ}(\mathrm{N})}$ and $U_{\mathrm{EQ}(\mathrm{S})}$ are zonal wind anomalies that are generated in the tropics and propagate to the mid- and high-latitudes. $U_{\mathrm{P}(\mathrm{N})}$ and $U_{\mathrm{P}(\mathrm{S})}$ are zonal wind anomalies that are generated in the polar regions and propagate to high-latitudes.

Westerly winds increase in regions close to the subtropical jet $\left(\mathrm{J}_{\mathrm{T}}\right)$ and the polar front jet $\left(\mathrm{J}_{\mathrm{P}}\right)$, so that the maximum variation of westerly angular momentum is found at the tropopause.

(2) Planetary scale zonal mean wind anomalies at high-latitudes of both hemispheres over tropopause also have intra-seasonal changes. A significant positive correlation is observed between the AO index series and the zonal wind anomalies on the tropopause at high-latitudes in the Northern Hemisphere, and a higher positive correlation exists between the AAO index series and the high-latitude zonal wind anomalies in the Southern Hemisphere. The physical nature of the AO/AAO and the planetary scale high-latitude zonal wind anomalies on the tropopause of both hemispheres represents the intensity changes of the polar fronts. The planetary scale zonal wind anomalies combine with the westerly jet at high-latitudes near the tropopause where the polar front $\left(\mathrm{J}_{\mathrm{P}}\right)$ intensity is greatly changed. There are no correlations between the AO and AAO series, nor between those mid- and high-latitude planetary scale zonal wind anomalies from one hemisphere to another, because the zonal mean wind anomalies at midand high-latitudes are affected by the planetary scale zonal wind anomalies not only from the equator $\left(U_{\mathrm{EQ}}\right)$ but also from the high-latitudes and polar regions $\left(U_{\mathrm{P}}\right)$.

(3) The inter-annual planetary scale zonal wind anomalies can propagate along the tropopause from the tropical to the polar-front regions in high-latitudes. The propagation process lasts for about 4 years. Further analysis showed the intra-seasonal (40-60-d) zonal wind anomalies on the tropical tropopause can spread to extra-tropical regions by a propagation mechanism of abnormal circulations of the Hadley and Ferrel cells. The intra-seasonal oscillation of the planetary scale tropical zonal wind is different from the tropical MJO, which results from tropical local air-sea interaction. The MJO can be analyzed by using the regional scale atmospheric anomalies based on physical decomposition.
(4) The intra-seasonal planetary scale zonal wind anomalies $\left(U_{\mathrm{P}(\mathrm{N})}\right.$ and $\left.U_{\mathrm{P}(\mathrm{S})}\right)$ generated in the polar atmosphere can spread to high-latitudes by an anomaly of the meridional polar cells. Zonal wind anomalies from the polar tropopause and from the tropical tropopause $\left(U_{\mathrm{EQ}(\mathrm{N})}\right.$ and $\left.U_{\mathrm{EQ}(\mathrm{S})}\right)$ on the inter-annual and intra-seasonal timescales could meet at high-latitudes. The planetary-scale circulation oscillations in the atmosphere such as the AO, AAO and SO, and the planetary scale zonal and meridional wind anomalies at the tropopause ultimately reflect the result of the planetaryscale thermal contrast variations from the tropics and polar regions.

(5) The Rossby zonal index, the AO index, and the AAO index separately reflect the geopotential height (or pressure) gradients in the mid- and high-latitudes over the two hemispheres. They oscillate in a see-saw fashion in the meridional direction. But actually, they result from the meridional propagation of planetary scale zonal wind anomalies. At the tropopause, the inter-annual atmospheric anomalies are driven by the ENSO cycle, and the intra-seasonal atmospheric anomalies are driven by intra-seasonal heat perturbations in the tropics and two polar regions.

This work was supported by the National Natural Science Foundation of China (40975039). Authors would like to thank the two reviewers for their comments and suggestions.

1 Rossby C G. Relation between variations in the intensity of the zonal circulation of the atmosphere and the displacements of the semipermanent centers of action. J Mar Res, 1939, (2): 38-55

2 Thompson D W J, Wallace J M. The Arctic Oscillation signature in wintertime geopotential height and temperature fields. Geophys Res Lett, 1998, 25: 1297-1300

3 Thompson D W J, Wallace J M. Annular modes in the extratropical circulation: Part I: month-to-month variability. J Clim, 2000, 13: 1000-1016

4 Gong D Y, Wang S W. Definition of Antarctic Oscillation index. Geophys Res Lett, 1999, 26: 459-462

5 Fan L J, Li J P, Wei Z G, et al., Annual variations of the Arctic Oscillation and the Antarctic Oscillation (in Chinese). Chin J Atm Sci, 
2003, 27: 419-424

6 Yang X Y, Guo P W, Hu Y W. Zonal symmetry structure of Arctic Oscillation (in Chinese). Plateau Meteorol, 2005, 24: 405-410

7 Gong D Y, Ho C H. Arctic Oscillation signals in the East Asian summer monsoon. J Geophys Res, 2003, 108: 4066

8 Fan K, Wang $\mathrm{H}$. Antarctic oscillation and the dust weather frequency in North China. Geophys Res Lett, 2004, 31: L10201

9 Song L C, Yu Y X, Sun X Y, et al. Relationship between Artic Oscillation and spring severe sandstorm in North China (in Chinese). Plateau Meteorol, 2002, 21: 8-13

10 Gong D Y, Wang S W, Zhu J H. Arctic Oscillation influence on daily temperature variance in winter over China. Chin Sci Bull, 2004, 49: 637-642

11 Berlage H P. The Southern Oscillation and world weather. Meded Verhandl, 1966, 88: 1-152

12 Bjerknes J. A possible response of the atmospheric Hadley circulation to equarial anomalies of ocean temperature. Tellus, 1966, 18: $820-829$

13 Bjerknes J. Atmospheric teleconnections from the equatorial Pacific.
Mon Weather Rev, 1969, 97: 163-172

14 Qian W H, Chou J F. Atmosphere-earth angular momentum exchange and ENSO cycle (in Chinese). Sci China Ser D Earth Sci, 1996, 26: 80-86

15 Madden R D, Julian P R. Detection of a 40-50 day oscillation in the zonal wind in the tropical Pacific. J Atmos Sci, 1971, 28: 702-708

16 Madden R A, Julian P R. Observations of the 40-50-day tropical oscillation-A review. Mon Weather Rev, 1994, 122: 814-837

17 Kalnay E, Kanamitsu M, Kistler R, et al. The NCEP/NCAR 40-year Reanalysis Project. Bull Am Meteorol Soc, 1996, 77: 437-471

18 Smith T M, Reynolds R W, Peterson T C, et al. Improvements to NOAA's historical merged land-ocean surface temperature analysis (1880-2006). J Clim, 2008, 21: 2283-2296

19 Qian W H. Physical decomposition principle of regional-scale transient anomaly (in Chinese). Chin J Geophys, 2012, 55: 1439-1448

20 Wolter K, Timlin M S. Measuring the strength of ENSO events-how does 1997/98 rank? Weather, 1998, 53: 315-324

21 Mann M E. Smoothing of climate time series revisited. Geophys Res Lett, 2008, 35, doi: 10.1029/2008GL034716

Open Access This article is distributed under the terms of the Creative Commons Attribution License which permits any use, distribution, and reproduction in any medium, provided the original author(s) and source are credited. 